\title{
EPIDEMIOLOGICAL VALUE OF LIPOPOLYSACCHARIDE AND HEAT-MODIFIABLE OUTER-MEMBRANE PROTEIN SEROTYPING OF GROUP-A STRAINS OF NEISSERIA MENINGITIDIS
}

\section{J. MCL. GRIFFISS}

\section{Channing Laboratory, Harvard Medical School and Brigham and Women's Hospital, 180 Longwood Avenue, Boston, MA 02115-5899, USA}

\begin{abstract}
SUMMARY. The lipopolysaccharide (LPS) and heat-modifiable outermembrane protein $\left(\mathrm{P}^{\prime}\right)$ serotypes of 39 coded strains of group-A Neisseria meningitidis isolated from patients during seven geographically and temporally separate outbreaks of infection were determined blindly. LPS serotype discriminated between strains from different outbreaks and between strains of differing sulphadiazine sensitivity within a single outbreak. Thirty-seven strains were of three separate serotypes and no strain was of multiple serotypes. In contrast, $\mathbf{P}^{\prime}$ serotypes did not discriminate between strains. Multiple serotypes for single strains and among strains from a single outbreak were the rule. LPS serotyping appears to be a useful epidemiological tool for distinguishing group-A strains of $N$. meningitidis.
\end{abstract}

\section{INTRODUCTION}

Serotyping of strains of Neisseria meningitidis of serogroups B, C, and Y has yielded useful epidemiological information (Jones and Tobin, 1976; Griffiss et al., 1977; Broud, Griffiss and Baker, 1979; Danielsson and Olcén, 1979; Poolman, Hopman and Zanen, 1980). The epidemic potential of strains of these serogroups is related, in part, to their serotype (Broud et al., 1979). The serotypes of group-A strains of N. meningitidis have only recently been investigated (Sippel and Quan, 1977; Quan and Sippel, 1979; Zollinger and Mandrell, 1980). Because all group-A strains appear to have a common major outer-membrane protein (Sippel and Quan, 1977), strain differentiation on the basis of protein serotype antigens or bactericidal reactions is difficult (Griffiss et al., 1977; Quan and Sippel, 1979). Zollinger and Mandrell (1980) recently extended their lipopolysaccharide (LPS) serotyping system to group-A strains and also reported differentiation of group-A strains on the basis of heat-modifiable outer-membrane proteins $\left(\mathrm{P}^{\prime}\right)$ of lower molecular weight than that of the major outer-membrane protein. To determine whether either of these serotype antigen complexes can be used to discriminate between epidemiologically discrete strains, they were characterised in strains of group-A $N$. meningitidis isolated from patients during seven separate outbreaks. 


\section{MATERIALS AND METHODS}

Group- $A$ N. meningitidis strains. Thirty-eight strains were selected from the culture collection of the Department of Bacterial Diseases, Walter Reed Army Institute of Research, Washington, DC. Ten strains were isolated from US military personnel or their dependents posted in the Federal Republic of Germany during January 1964-December 1967 and represented all group-A strains routinely forwarded during that period to the Walter Reed Army Institute of Research. Three strains were isolated in Morocco in March 1967; although isolated from US military dependents, they were part of a major epidemic in Morocco which reached its peak in that month. Twelve strains were isolated in the 'meningococcal belt' (Sahel) of Africa (Lapeysonnie, 1963), six from Mali during a massive epidemic in 1969 and six from Ghana during a seasonal outbreak in 1970. Five strains were isolated in four Finnish cities during a country-wide epidemic in 1975 (kindly provided by Dr P. H. Mäkelä, Helsinki). Five strains were isolated in Manitoba in 1971 during a focal outbreak among American Indians residing in the Winnipeg area (Dr A. R. Ronald, University of Manitoba). Three strains were isolated in Brazil in 1972 during a country-wide epidemic.

All strains were from patients with disseminated meningococcal disease and there was no known selection bias. Strains were stored in the lyophilised state and tested within one to six passages of original isolation. They were shown to be $N$. meningitidis by characteristic carbohydrate utilisation and serogrouped by the slide-agglutination technique (Evans, Artenstein and Hunter, 1968).

Serotyping was by the solid-phase radioimmunoassay inhibition technique of Zollinger and Mandrell (1980), kindly performed by R. E. Mandrell. Strains were coded so that serotyping was blind. Only $\mathbf{P}^{\prime}$ and LPS serotypes unique to group-A strains are reported here.

Sensitivity to sulphonamides. Tests of sensitivity to sulphadiazine were carried out by standard methods (Artenstein, Schneider and Tingley, 1971). A minimal inhibitory concentration (MIC) of $10 \mu \mathrm{g} / \mathrm{ml}$ was used as the upper limit of sensitivity.

\section{RESULTS}

The LPS and $\mathrm{P}^{\prime}$ serotypes of the 38 strains of $N$. meningitidis are given in tables I and II respectively. The LPS serotypes provided reasonable discrimination. All but one strain were typable and all three serotypes were represented. Multiple serotypes

TABLE I

Lipopolysaccharide serotypes of group-A strains of $N$. meningitidis isolated druing several epidemics

\begin{tabular}{|c|c|c|c|c|c|}
\hline \multirow[b]{2}{*}{ Epidemiological set } & \multirow{2}{*}{$\begin{array}{c}\text { (Number of } \\
\text { strains) }\end{array}$} & \multicolumn{4}{|c|}{ Number of strains of LPS type } \\
\hline & & L9 & L10 & L11 & NT \\
\hline \multicolumn{6}{|l|}{ US Military } \\
\hline Germany 1964-1967 & (10) & $\ldots$ & 9 & 1 & $\ldots$ \\
\hline Morocco March 1967 & (3) & $\ldots$ & 3 & $\ldots$ & $\ldots$ \\
\hline Africa & & & & & \\
\hline Mali 1969 & (6) & $3(\mathrm{~S})$ & $3(\mathrm{R})$ & $\ldots$ & $\ldots$ \\
\hline Ghana 1970 & (6) & 6 & $\cdots$ & $\cdots$ & $\cdots$ \\
\hline $\begin{array}{l}\text { Furope } \\
\text { Finland } 1975\end{array}$ & (5) & $\ldots$ & $\ldots$ & 4 & 1 \\
\hline North America & & & & & \\
\hline $\begin{array}{l}\text { Manitoba } 1971 \\
\text { South America }\end{array}$ & (5) & 2 & 3 & $\cdots$ & $\cdots$ \\
\hline Brazil 1972 & (3) & & 3 & & \\
\hline All & (38) & 11 & 21 & 5 & 1 \\
\hline
\end{tabular}

LPS = lipopolysaccharide; NT= not typable; $(\mathrm{S})=$ sensitive to sulphadiazine; $(\mathrm{R})=$ resistant to sulphadiazine. 
TABLE II

Heat-modifiable protein serotypes of group-A strains of $N$. meningitidis isolated during several epidemics

\begin{tabular}{lc|rrrrrr}
\hline & & \multicolumn{6}{|c}{ Number of strains of $\mathrm{P}^{\prime}$ type } \\
\cline { 5 - 8 }$\quad$\begin{tabular}{c} 
Eumber of \\
\cline { 5 - 8 }
\end{tabular} & strains
\end{tabular}

$\mathrm{P}^{\prime}=$ heat modifiable protein; $\mathrm{NT}=$ not typable

were not expressed by single strains and, with two exceptions, strains from a single epidemiological set were of the same serotype. In one exceptional set, the Mali isolates, all the L9 strains were sensitive to sulphadiazine while all three L10 strains were resistant. The concordance between these two separate markers of strain difference emphasises the ability of LPS serotyping to discriminate validly between strains - even those isolated during the same outbreak. Sulphadiazine sensitivity was not determined for the strains from Manitoba.

In contrast, the $\mathrm{P}^{\prime}$ serotypes did not provide useful discrimination. Not only did individual strains have multiple serotypes but the pattern of serotypes did not segregate within epidemiological sets. While five separate serotypes were represented, four strains were not typable.

\section{Discussion}

Serotyping based on LPS antigen complexes or heat-modifiable proteins has not previously been used in epidemiological studies. While it is clear that the latter would not provide useful information, the discriminatory ability of LPS serotypes appears promising, even accepting the small number of strains in each epidemiological set. This is particularly so because neither major outer-membrane protein nor bactericidal serotyping of group-A strains is feasible. The occurrence of three separate LPS serotypes in these geographically and temporally separated outbreaks emphasises that no single serotype is associated with the "epidemic virulence" of group-A strains. The occurrence of strains of two separate LPS serotypes and sulphadiazine sensitivities in the same outbreak may reflect the greater importance of the capsular polysaccharide in the causation of that epidemic as opposed to those in which a single serotype occurs (Broud et al., 1979). An association between serotype and sulphadiazine sensitivity has previously been observed in group-C, type-II strains (Griffiss et al., 1977).

In addition to epidemiological discrimination, serotyping may be useful in 
indicating surface antigens of bacteria that are relevant to human immunity. The antigenic specificity of protective, non-capsular antibodies remains unclear but bactericidal antibodies directed at LPS antigens of group-Y strains of $N$. meningitidis are found in normal human sera (Griffiss and Goroff, 1981). The epidemiological usefulness of LPS serotyping of strains of $N$. meningitidis, as well as the importance of LPS antigens in human immunity to these strains, requires confirmation in larger scale epidemiological studies.

Supported by Research Career Development Award \#AI 00328 and Grant \#A1 15241, both from the National Institutes of Health of the USA. I would like to thank Ms Barbara Chamberlain for assistance in the preparation of this manuscript.

\section{REFERENCES}

Artenstein, M. S., Schneider, H. And Tingley, M. D. 1971. Meningococcal infections. I. Prevalence of serogroups causing disease in U.S. Army personnel in 1964-70. Bulletin of the World Health Organization, 45, 275-278.

Broud, D. D., Griffiss, J. McL. AND BAKER, C. J. 1979. Heterogeneity of serotypes of Neisseria meningitidis that cause endemic disease. Journal of Infectious Diseases, 140, 465-470.

DANIELSSON, D. AND OlCÉN, P. 1979. Rapid serotyping of groups A, B, and C meningococci by rocket-line immunoelectrophoresis and co-agglutination. Journal of Clinical Pathology, $32,136-142$.

Evans, J. R., Artenstein, M. S. And Hunter, D. H. 1968. Prevalence of meningococcal serogroups and description of three new groups. American Journal of Epidemiology, 87, 643-646.

Griffiss, J. McL., Broud, D. D., Silver, C. A. And Artenstein, M. S. 1977. Immunoepidemiology of meningococcal disease in military recruits. I. A model for serogroup independency of epidemic potential as determined by serotyping. Journal of Infectious Diseases, 136, 176-186.

GrIFFISS, J. MCL. AND GoROFF, D. K. 1981. Immunological cross-reaction between a naturally occurring galactan, agarose, and an LPS locus for immune lysis of Neisseria meningitidis by human sera. Clinical and Experimental Immunology, 43, 20-27.

Jones, D. M. AND TOBIN, B. M. 1976. Serotypes of group B meningococci. Journal of Clinical Pathology, 29, 746-748.

LAPEYSSONIE, L. 1963. La méningite cérébro-spinale en Afrique. Bulletin of the World Health Organization, 28 (suppl.), 1-114.

PoOlman, J. T., Hopman, C. T. P. ANd Zanen, H. C. 1980. Immunochemical characterization of Neisseria meningitidis serotype antigens by immunodiffusion and SDS -polyacrylamide gel electrophoresis immunoperoxidase techniques and the distribution of serotypes among cases and carriers. Journal of General Microbiology, 116, 465-473.

QuAN, A. L. AND SiPPEL, J. E. 1979. Evaluation of bactericidal assay in serotyping Neisseria meningitidis group A. Canadian Journal of Microbiology, 25, 929-931.

SiPPEL, J. E. AND QuAN A. 1977. Homogeneity of protein serotype antigens in Neisseria meningitidis group A. Infection and Immunity, 16, 623-627.

Zollinger, W. D. AND Mandrell, R. E. 1980. Type-specific antigens of group A Neisseria meningitidis: lipopolysaccharide and heat-modifiable outer membrane proteins. Infection and Immunity, 28, 451-458. 